\title{
Driver Drowsiness Detection and Vehicle diagnostics using Android Bluetooth
}

\author{
Prof. R. R. Jadhav ${ }^{1}$, Mayuri H. Godse ${ }^{2}$, Supriya P. Pawar ${ }^{3}$, Pallavi M. Baravkar ${ }^{4}$ \\ M.Tech (E\&TC), Assistant Professor (ETRX Dept)., COEManjari (Bk), Pune, India ${ }^{1}$
}

BE, ETRX Department, COEM, Pune, India ${ }^{2,3,4}$

\begin{abstract}
Drowsiness is identified using eye blink count. The alcohol consumption is also verified during the starting process of the vehicle. Drunken driving is prevented. Continuously temperature monitoring. Eye blinks count and alcohol detection using android Bluetooth, buzzer indication if driver is not wearing seat belt. Stepper motor controls the fuel tank for drowsy person to prevent accident. GPS location indication and SMS alert in case of accident.
\end{abstract}

Keywords: MQ3- alcohol sensor, IR-eye blink sensor Thermister- temperature sensor, GPS- global positioning System.

\section{INTRODUCTION}

The Growing no of fatal accidents due to drivers line. It has high performance coupled with low power negligence or not following safety precautions makes it consumption reduced instruction set computer hardware necessary to develop a system which ensures safe driving architecture design for C language AVR line provides a which will in turn ensures safety of driver as well as co full range processing power from small and pin processor passengers.A system which will start ignition only if the to complex 100 pin processor.

driver passes test for driver authentication, alcohol C. Vehicle speed limit alerting and crash detection consumption and seat belt. The driver will be allowed to system.

start ignition only after he validates himself while the This paper is design in order to avoid accidents and alert vehicle is in motion it will capture values for speed the drivers about speed limit. Many Systems provide road control, it will ensures engine temperature is maintained safety and has proposed various methods for speed and the touch sensor ensures driver is holding steering limitation and accident avoidance but to actually control while driving another feature of the system is the the vehicles speed in real time is very difficult so instead drowsiness sensor which start a buzzer or start interaction with the driver so he does not feel sleepy to access diagnostics data of the vehicle as early as possible is important to avoid serious faults. Early detection and correction will increase safety up to a very large extends using GPS the location of the vehicle can be obtained with the help of longitude $\mathrm{n}$ longitude values. ones the right defects are obtained then instruction can send to the driver as to how to handle the situation.SMS will be send to relatives in case of accidents.

\section{METHODOLOGY}

\section{A. Android Based Vehicle Diagnostic system}

This system provides very user friendly and low cost hardware for vehicle diagnostics. The mobile device which is android based helps in creating an on board vehicle diagnostic system. The mobile device application interacts with the hardware unit with the help Bluetooth and acquires vehicle parameters obtained from the ECU of the vehicle. These values can be viewed by the driver of the vehicle as well as the server from which the vehicle can be administered by the owner of the vehicle or can be stored in a database for further maintenance.

\section{B. Design vehicle checking system based on AVR}

ATMEL AT mega 32 is used as representative sample of the AVR line.The knowledge we gain on the AT mega 32 can be easily translate to every other microcontroller AVR of controlling the speed the driver is alert about his speed so that he can reduce his speed to a safe limit

D. Basic Method Of system

Recently there has been an enormous increase in road accident due to sleep derivation resulting to driver fatigue. The driver losses control of the vehicle when he falls as sleep which leads to loss of many lives.

This is because of the fact that the driver is not able to control his vehicle when he is sleep and by the time he realizes it there is an accident. The vehicle is at a very high speed on highways due to this many automobile companies are trying to research on to how and accident which occurs due to driver fatigue can be prevented. In this project we will generate a model which can prevent such accident.
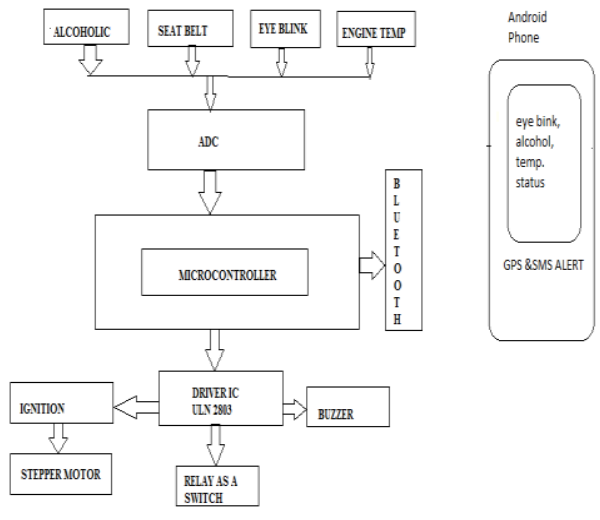

Fig.1 Architecture of system 
The purpose of such model is to advance assenting to detect fatigue symptoms in driver and control the speed of vehicle to avoid accidents. The main components of the system consist of an eye blink sensor for driver blink acquisition and adaptive speed controller designed using stepper motor for providing precise positioning throttle valve to control to control the speed of vehicle.

\section{E. Android phone and sensor system.}

The Android phone use to display all the data the android phone will have application which helps driver to authenticate himself and view details of the vehicle.

i. Speed sensor: The speed sensor will track speed of vehicle and ensures it does not exceed a particular limit. If exceed a particular limit will raise or some kind of notification will be given to the driver to reduce speed.

ii. Fuel Level Sensor: The fuel level sensor makes sure that the fuel level is maintained and the level is not under a particular level this sensor makes sure the driver fills in amount of fuel as said by owner and there is transparency.

iii. Seat Belt Sensor: The seat belt sensor is based on push button. This sensor makes sure driver is using his seat belt and if not he will be notified to do so.

iv. Alcoholic Sensor: It is use for detecting alcohol concentration highly sensitive and fast response in at time breathing. It provides resistive output based on alcoholic concentration.

Temperature Sensor: In order to avoid unusually heating of the vehicle this sensor will raise and alarm and necessary precautions will be taken.

\section{III.CONCLUSION}

The developed embedded system is prototype vision system for the real-time monitoring of a driver's vigilance. It is based on a hardware system for a real-time acquisition of driver's status using an active IR illuminator and the implementation of software algorithms for the real-time monitoring of the fatigue level of a driver. These visual parameters are the PERCLOS, eye closure duration, blink frequency. The system is fully autonomous; it can initialize automatically, and reinitialize when necessary. It was tested using different sequences recorded in real driving conditions with different users during several hours. This project involves measure and controls through alcohol sensor and eye blink using IR sensor. In each sequence, several fatigue behaviours were tested during the test. The system works robustly at night and yielding an accuracy percentage close to $95 \%$.

\section{REFERENCES}

[1] J. Connor, R. Norton, S. Ameratunga, E. Robinson, I. Civil, R. Dunn,J. Bailey, and R. Jackson, "Driver sleepiness and risk of serious injuryto car occupants: Population based case control study," Brit. Med. J.,vol. 324, pp. 1125-1128, 2002

[2] K. A. Brookhuis, D. D.Waard, and S. H. Fairclough, "Criteria for drivermpairment," Ergonomics, vol. 46, pp. 433-445, 2003

[3] J. A. Horne and L. A. Reyner, "Sleep related vehicle accidents," Brit.Med. J., vol. 310, pp. 565-567, 1995.
[4] G. Maycock, "Sleepiness and driving: The experience of UK car drivers," J. Sleep Res., vol. 5, pp. 229-237, 1996.

[5] T. Hong and H. Qin, "Drivers drowsiness detection in embeddedsystem," in Proc. IEEE Int. Conf. Vehicular Electronics and Safety,2007, pp. 1-5.

[6] "Sleep facts and stats," National Sleep Foundation. Washington, D.C.[Online]. Available: http://www.sleepfoundation.org/

[7] G. Maycock, "Sleepiness and driving: The experience of heavygoods vehicle drivers in the UK," J. Sleep Res., vol. 6, pp.238-244, 1997.

[8] Stephen H. Impairment of driving performance caused by sleep deprivation or alcohol. A comparative study. Human Factors, 1999, 41(1):118-128

[9] Hayashi K, Ishihara K, Hashimoto $H$, et al. Individualized Drowsiness detection during driving by pulse wave analysis With neuralnetwork. In: Proceedings of the 8th InternationalIEEE Conference on Intelligent Transportation Systems. Vienna, Austria, 2005: 901-906.

[10] A. Vuckovic, V. Radivojevic, A. Chen, and D.Popovic"Automatic recognition of alertness anddrowsinessfromeeg by an articialneuralnetwork," Medical Engineering and Physics, vol.24, pp. 349-360, March 2002

[11] European Transport Safety Council, "The Roleof Driver Fatigue in Commercial RoadTransport Crashes", 2001.

[12] AAA Foundation for Traffic Safety, "The Role ofDriver Distraction in Traffic Crashes", availableathttp://www.aaafoundation.org/pdf/distraction.pdf, May 2001 .

[13] Takei, Y., Furukawa, Y., "Estimate of driver'sfatigue through steering motion", SMC 05, Vol.2, pp. 1765-1770, 2005.

[14] J. Healey and R. Picard, "SmartCar: Detectingdriver stress," in Proc.15th Int. Conf. PatternRecognition, Barcelona, Spain, 2000, vol. 4,pp.218-221.

[15] M. Devi and P. Bajaj, "Driver fatigue detectionbased on eye tracking,'Emerging Trends inEngineering and Technology, 2008. ICETET'08. First International Conference on, 2008, pp.649-652. 